\title{
(息)
}

Citation:

Gough, B (2016) Men's Depression Talk Online: A Qualitative Analysis of Accountability and Authenticity in Help-Seeking and Support Formulations. PSYCHOLOGY OF MEN \& MASCULINITY, 17 (2). 156 - 164. ISSN 1524-9220 DOI: https://doi.org/10.1037/a0039456

Link to Leeds Beckett Repository record:

https://eprints.leedsbeckett.ac.uk/id/eprint/2689/

Document Version:

Article (Accepted Version)

The aim of the Leeds Beckett Repository is to provide open access to our research, as required by funder policies and permitted by publishers and copyright law.

The Leeds Beckett repository holds a wide range of publications, each of which has been checked for copyright and the relevant embargo period has been applied by the Research Services team.

We operate on a standard take-down policy. If you are the author or publisher of an output and you would like it removed from the repository, please contact us and we will investigate on a case-by-case basis.

Each thesis in the repository has been cleared where necessary by the author for third party copyright. If you would like a thesis to be removed from the repository or believe there is an issue with copyright, please contact us on openaccess@leedsbeckett.ac.uk and we will investigate on a case-by-case basis. 
Running head: Men, depression and online support

Men's depression talk online: a qualitative analysis of accountability and authenticity in help-seeking and support formulations

Brendan Gough, Leeds Beckett University, UK

Word count (excluding references): 6876

Author Footnotes

Correspondence regarding this paper should be sent to Brendan Gough at b.gough@leedsbeckett.ac.uk 


\begin{abstract}
We know that twice as many women are diagnosed with depression as men, and that ‘masculinity’ issues can inhibit men from conceding psychological distress. However, research to date has been limited to studies of men diagnosed or assessed as depressed, and analyst-driven masculinity concepts have arguably structured the data analysis. One way around these issues is to study how men construct depression themselves - without the influence of a researcher - and how they support other men to manage their depression. This paper reports on a qualitative constructionist thematic analysis of mens' talk on an online support forum, and focuses on how men work up a credible account of depression (first posts) - and how peers respond to different accounts of depression (response posts). Our analysis indicates that although medical discourse (e.g. diagnosis) is referenced as essential for validation of depression accounts, those men without a diagnosis may still receive support if their account is designed in particular ways (e.g. is detailed, cites extenuating circumstances, positions the individual as proactive). More generally, the analysis highlights the delicate and complex discursive work involved in depression accounts, and we reflect on how issues of accountability and authenticity may be mitigated in mental health service provision for men.
\end{abstract}

Keywords: Men, masculinity, depression, qualitative, support 


\section{Men's depression talk online: a qualitative analysis of accountability and authenticity in help-seeking and support formulations}

Depression is a common mental health problem which can be caused by different factors, ranging from environmental to neurochemical, which may be experienced for a sort period only or persist long term, and which can present with a range of symptoms, including low mood, lack of energy, loss of appetite, inability to experience pleasure and negative selftalk (see NICE, 2009a). It is well established that fewer men than women are treated for depression-related disorders within England (Richards \& Borglin, 2011), reflecting a similar situation more generally (Addis, 2008; Addis \& Cohane, 2005). Psychologists have suggested that this is a result of widespread under-diagnosis of depression amongst men, rather than a sex-difference in actual prevalence (Addis, 2008; Addis \& Cohane, 2005), although this is a complex issue; for example, we know that some groups of men are not reluctant to seek under certain circumstances (see Robertson \& Williams, 2009). When men do come forward with mental health issues, however, there may be a lack of appropriate support (see Morrison, Trigeorgis and John, 2014) which means that difficulties may be exacerbated, leading to poor coping strategies (e.g. excessive alcohol consumption) and, in some cases, an increased risk of suicide. It is well known that the male suicide rate is three to four times higher than that for females (Oliffe, Han, Ogrodniczuk, Phillips, \& Roy, 2011), and depression is one of the most common factors implicated in suicide cases (Möller-Leimkühler, 2003). Clearly, understanding how men construct and negotiate distress and vulnerability is of vital importance.

Although there has historically been a lack of academic interest concerning men and depression, this area has recently become the focus of increasing attention from psychologists and others (Addis, 2008; Ridge, Emslie, \& White, 2011). Quantitative research has 
highlighted sex differences in coping with depression, for example indicating that women adopt more (positive) coping strategies compared to men (e.g. Tamres, Janicki \& Helgeson, 2006). Work focusing specifically on men’s coping styles implicates the role of masculinity norms, including self-reliance, emotional repression and risk-taking (Mahalik, Burns \& Syzdek, 2007). Complementing this survey-based research, and in common with much contemporary cross-disciplinary research on masculinities and men’s health, much recent research on male mental health has deployed qualitative methods, reflecting a more general trend in health research where patient/client/lay voices are valued (e.g. Ridge, Emslie, \& White., 2011). Many of these qualitative studies adopt a social constructionist perspective with respect to gender, emphasising complexity, fluidity and social context in the presentation of masculinities and femininities (Addis \& Cohane, 2005).

Since gender construction is both local and dynamic (Addis \& Cohane, 2005), the ways in which men actually go about doing masculinity will vary according to the social resources available to them (Messerschmidt, 1993). For example, whilst some men could perform risk, a conventional marker of masculinity, by partaking in extreme sports, others might do so through the adoption of poor health practices, such as binge drinking (Courtenay, 2000). As a result, men enact multiple masculinities, with particular ones being treated as either locally hegemonic (dominant) or marginalised dependant on context (Connell, 2005; Connell \& Messerschmidt, 2005), rather than consistently modelling themselves on a single idealised male prototype as might be traditionally supposed. From this perspective, qualitative studies have generally focused on health-defeating or 'maladaptive' male coping strategies linked to hegemonic masculinities, such as self-reliance (Emslie et al., 2006; Johnson et al., 2012; Sierra-Hernandez et al., 2014;), not expressing difficult emotions (Oliffe et al., 2010), and risk-taking avoidance behaviours such as excessive alcohol consumption (Oliffe et al., 2012). Consequently, male depression has been characterised as 'masked' (e.g. presenting as anger), 
deemed 'atypical', or managed in a 'maladaptive’ way (Addis, 2008).

In some qualitative studies there has been some (although limited) attention to the deployment of hegemonic masculinity ideals to promote help-seeking and service use; for example, seeking support may be redefined by some men as demonstrating autonomy, strength, or even heroism (e.g. Roy, Tremblay \& Roberts, 2014). Relatedly, it has been reported that men may prefer or take up an active, pragmatic, problem-solving approach whether in therapy (Emslie et al., 2007) or in their everyday contexts e.g. physical exercise (Valkonen \& Hänninen, 2013). In addition, some qualitative research has reported that a minority of men may interpret their depressed status as signalling a positive difference from other men and masculinity norms e.g. more sensitive/ less constrained (Emslie et al, 2006). Similarly, some research has shown that depression may present an opportunity to rethink and reconstruct masculinities along alternative but progressive lines where, for example, emotional communication is valued (e.g. Oliffe et al., 2011). A few studies have indicated that some men appreciate the emotional support offered by partners, family and peers (Ramirez \& Badger, 2014), including fellow depression sufferers, who can help to normalise the situation (Cutcliffe et al., 2013).

To date, qualitative research with men suffering from depression has been dominated by interview-based work with those men who have received a diagnosis of, or have been assessed as suffering from, depression (e.g. Rochlen et al., 2010). While qualitative interviews can generate valuable insights into interviewee perceptions and narratives, this method has been criticised by discourse analysts for focusing on individual accounts rather than the social interaction between researcher and participant - and for neglecting how analysts deploy their own theoretical categories (e.g. masculinity constructs) to structure their analyses (see Potter \& Hepburn, 2006). What is currently missing from the evidence base is research focusing on how men talk about depression in more 'naturalistic' settings i.e. with 
peers - and without researchers being present, as Ridge et al. (201) note:

Allowing men to define distress for themselves in qualitative research will probably open up important insights into ‘invisible’ aspects of their emotional life (p. 154)

An additional benefit of examining such talk is that we can consider how men offer support to each other, a growing area of interest in the field of men’s health (see Bennett \& Gough, 2013; Seymour-Smith, 2013). There is some debate over the meaning of 'naturalistic' however (see Speer, 2008) and we do not mean to suggest that the online setting and accounts analysed here are completely 'naturalistic'; we are simply highlighting that researcher absence allows us to examine how men talk to each other in this particular context.

The current paper therefore reports on a study of men's depression talk in an online discussion forum environment. The online environment is pertinent also because, increasingly, e-mental health initiatives are being set up to engage men because so few access more traditional psychological services (see http://www.mensdepressionhelpyourself.ubc.ca/ for an example). Indeed, there are some indications from online service providers that services such as counselling by email, text or online chat are more popular with men than women, although to date the evidence is thin. More generally, there is a trend in male mental health promotion towards community-based initiatives, including web-based, featuring peer support, mentoring and non-medical language (see Robertson et al., 2014). Research on online support groups has developed greatly in the last ten years or so, focusing on how such ‘communities of practice’ function to monitor group membership and identity, and how support is designed, delivered and received - including online forums concerning mental health issues and depression (e.g. Giles \& Newbold, 2013; Horne \& Wiggins, 2009; Lamerichs \& te Molder, 2003; Vayreda \& Antaki, 2009). In particular, the issue of accountability has been examined i.e. the discursive work undertaken to construct an identity as legitimately depressed (rather than, say, attention-seeking or 'phony'), and it has been 
noted, for example, that accounts often take on a narrative format which locate the problem in time and space, thereby giving the story an authentic feel (Lamerichs \& te Molder, 2003).

Influenced by this work, we take a constructionist thematic analysis approach to these data (e.g. Braun \& Clarke, 2006), a discursively inflected approach which considers aspects of language use but without the micro sequential analysis associated with discursive psychology or conversational analysis (see Potter, 1996). We are interested in how men present with an account of depression, and how this account is responded to by other men on the forum. As mentioned, previous work on men and depression has been interview-based, focused on men with a diagnosis, and informed by masculinity concepts. In contrast, our approach does not presume that gender is pertinent, and we set out to examine if and how both 'masculinity' and 'depression’ are referenced, made relevant, and worked up in the accounts posted - and what particular actions are being performed by such accounts (e.g. establishing a 'legitimate' identity; formulating a request for support etc.). We also consider how these accounts are received by forum members, to what extent they are treated as authentic or otherwise. In examining how men define and deal with depression in a 'realworld' (online) setting, we can identify men's preferred language in articulating distress as well as the type of depression accounts which are most likely to garner sympathy and support from peers - regardless of whether such depression accounts reflect established diagnostic criteria. These insights could thus be valuable in male mental health promotion, where relevant terminology and formulations could be adopted to appeal to men in difficulty. In this way traditional psychological services could become more 'male-friendly', while alternative, community-based initiatives could be developed which feature non-medical language, peer support and mentoring (see Robertson et al., 2014).

\section{Method}

In adopting our constructionist thematic analysis approach, we are interested in the 
style as well as content presented in depression accounts, and in the ways in which such accounts are received (e.g. peer support or critique). As such, we draw on various concepts from discourse analysis and discursive psychology (e.g. Potter, 1996) - but we have not adopted a fully-fledged discursive psychological analysis for various reasons. Discursive Psychology (and conversation analysis) is mainly focused on conversational rules and dynamics featured in extended social interaction sequences transcribed in minute detail (see Potter, 2007) - the focus of this analysis is on first and second posts only in an online environment without access to audiovisual data and hence detailed transcription. Moreover, the key interest here is in individual constructions (first posts and responses) rather than how the interactions unfold and follow particular conversational rules. We highlight the key features of first posts, pointing in particular to those elements and practices which work (are received) as authentic. We note what is at stake for forum members - how they negotiate between different expectations (e.g. to be genuinely depressed but not passive) to settle on a version of events that is accepted by peers.

\section{Data}

We conducted an extensive search for relevant discussion forums featuring men talking to each other about mental health issues. We used several key phrases for this purpose, including 'men's health discussion forum', 'men's mental health discussion forum', and 'men and depression discussion forum'. Hundreds of hits were generated and we spent time assessing diverse websites and forums for relevance to our topic. Forums which did not relate to depression were excluded. As we wished to focus on men communicating with other men, forums which were dominated by women or which featured a high proportion of female contributors (most forums) were also excluded. Of course it is impossible to be totally confident about the (gender) identity of online contributors, but liberal use of gendered tags (e.g. female names) and references (husband, brother, father...) were helpful in this regard. 
Another important criterion related to the richness of online interactions; in other words, to what extent does the material provide us with sufficiently in-depth 'data' which could provide insights into our questions concerning the construction and negotiation of depression by men? In the end, only one website which hosted relevant forum discussions met our criteria - a broader men's health site based in the UK. Interestingly, the two forums identified within this site did not explicitly foreground depression as the key topic; instead, the following headings were used:

"In need of support: Need to off-load your problems?” (330 threads)

"Stressed out: Work, relationship or family giving you grief?”(165 threads)

We also came across (and included in our dataset) a further 150 threads where depression was explicitly mentioned, and another 31 threads with a focus on help-seeking. The forums featured on this men's health site are open to anyone, and those relating to mental health do not require a prior medical diagnosis (although some volunteer information about diagnoses during the interactions while others indicate that they have not [yet] sought medical advice). Moreover, these lay presentations of depression are not (necessarily) designed to reflect established diagnostic criteria, and in this analysis we do not evaluate the extent to which such accounts are medically sound. Instead, we examine how depression is defined in situ, and how such accounts are responded to by peers. Like many online support group forums, these forums are designed for peer-to-peer interaction, enabling information and advice to be shared among a ‘community of practice’ (see Gray, 2004; Wenger, 1998). Typically, local norms, common practices and preferred identities emerge over time within such online communities; with forums devoted to male weight loss, for example, particular norms around masculinity (e.g. endurance of pain), body practices (e.g. gym work) and the policing of emotions (e.g. 'no girly stuff') become established (see Bennett \& Gough, 2012). 
It is normally presumed that help-seeking online is a preliminary step before formal advice is pursued (e.g. consultation with doctor), and as noted above all research to date has recruited men who already had been diagnosed with depression. So, this research presents a valuable opportunity to examine an under-researched group - undiagnosed men presenting with depression (although when the data were analysed we noted that both men with and without diagnoses posted about their experiences).

Our focus on one discussion forum and a limited number of threads (676 threads) is within the range of published qualitative research working with online data (e.g. Horne \& Wiggins, 2009; Stommel \& Koole, 2010), and modest datasets are common with respect to qualitative research across a range of methodologies, where the focus is on intensive rather than extensive analysis (e.g. Smith, 2004). This is especially true with discourse-based analyses of online (and offline) data (e.g. Horne \& Wiggins, 2009), and our analysis draws partly on discursive concepts. In the case of phenomena which have received little or no prior research attention it is also accepted that a focus on one case/site is justified, as in other studies of online data (Stommel \& Meijman, 2011); the novel focus here on 'naturalistic' homosocial discussion in one online forum around depression seems to fall into this category.

\section{Analytic process}

Having downloaded all available comments we initially read all the contributions and sifted out those that were unrelated or spam before commencing the analysis. The forum transcripts were analysed using a constructionist version of the thematic analysis procedure described by Braun \& Clarke (2006). This type of analysis was favoured as it would help establish patterns of meaning across the forum dataset in an inductive, data-driven fashion. Data analysis involved each thread being printed and read carefully. All data were then systematically coded, generating a wealth of specific, descriptive categories to begin 
with (e.g. 'stress', alcohol abuse', 'medication'). Periodically, initial categories were grouped together, with each cluster being allocated a meaningful label. The developing system of category clusters was regularly reviewed and refined, with analysis proceeding from many descriptive clusters towards fewer, more conceptual clusters which were thought to subsume most of the data (e.g. 'depression as a personal battle', 'barriers to help-seeking', 'social support') . Once themes were settled, a more discursive analysis was instigated. In other words, attention was paid to the ways in which key themes were oriented to, constructed and managed by forum users (i.e. discursive practices). Since a discussion forum foregrounds social interaction, a discursive sweep enables us to examine how accounts are worked up and how they function in this particular social context. This constructionist version of thematic analysis is specified in Braun \& Clarke (2006), and we have successfully used this methodology with other datasets (e.g. Bennett \& Gough, 2013).

Specifically, we considered how our themes were actually formulated in practice by those presenting a depression account - how was depression defined, and how was a request for help designed? In addition, we were interested in how these first posts were oriented to by others - which particular elements of first posts garnered the most attention and sympathy, for example? In short, we focused on how 'depression' was introduced and worked up in first posts, and how such accounts were responded to (second/response posts). We were particularly interested in those cases where men did not have a diagnosis of depression - how can they convince others that their 'depression' is genuine, and how do others respond? Such a focus on authenticity is common in discursive analyses of 'controversial' topics; for example, work on chronic fatigue syndrome has examined how sufferers seek to establish their condition as a legitimate medical complaint rather than a merely psychological (or imaginary) one (see Horton-Salway, 2001). The related discursive concept of 'accountability' is also relevant here i.e. attributions of blame and responsibility 
(see Potter, 1996). This is an issue here because in the absence of a medical diagnosis, individuals may have to work hard to convince others that their experiences are not (in part) self-inflicted or the result of poor personal decisions or lifestyles. Another associated concept here is ‘stake inoculation’ (Potter 1996) whereby speakers seek to emphasise that they have no personal investment or agenda in a topic i.e. they can offer a more dispassionate or 'objective' viewpoint - for example when offering advice to a peer presenting with depression. As with many discursively influenced studies, these concepts feature in the analysis which follows, although it must be stressed that the analysis is based on an inductive, bottom-up thematic analysis and therefore that the particular ways of doing authenticity and accountability in this context will be highlighted.

The analysis was initially conducted by the author and the first draft was then assessed by two colleagues who had access to the dataset. There was agreement between the coders about key themes, although often different labels were applied; for example, 'social support', 'lay advice', and 'community' were different theme labels applied to the same data extracts (second posts). There was also agreement that issues of authenticity and accountability were central to the accounts presented; we were all struck by the discursive efforts evident in first posts towards working up a 'legitimate’ account of depression, and the particular features of such accounts which produced sympathetic responses (e.g. medication talk, details about symptoms, reports of self-management). Other interesting features of the discussions were noted but not progressed here; for example, the widespread use of humour in constructing and responding to accounts of depression was highlighted by all three coders (this topic may be the focus of a future paper).

\section{Ethics}

Internet research such as this generates questions about ethical principles and safeguards. For example, online data can be deemed both public and private, but it is widely 
accepted that posts on open access sites (which are not password protected) are available to all and treated as such by contributors (e.g. Rodham \& Gavin, 2006; Walter \& Boyd, 2002). The online forum under consideration here is accessible by anyone and so issues of informed consent do not apply. However, researchers can take steps to maximise anonymity (BPS Guidelines for Internet Mediated Research, 2013) and as such we have changed usernames and thread titles have been altered and have neither specified the forum web address or the website to which the forum is attached. The research project was approved by the relevant University Ethics Committee.

\section{Findings}

As indicated above, we are interested in how men formulate their depression accounts, and how these are responded to by other men. We noticed very soon that for men who already have a diagnosis of depression, their accounts were much more straightforward than those who could not reference such a diagnosis. We begin with diagnosis and related talk, and responses to these accounts, before considering the much more complicated cases of men without diagnoses. In the main we present short extracts from original posts in order to foreground the particular feature being discussed, and where possible provide different examples of the feature in question to show variability.

\section{Diagnosis-related talk}

Unsurprisingly, for those men who had received a diagnosis of depression, their accounts of depression within initial posts cited this diagnosis, thereby helping to cement their illness report as genuine (rather than, say, a subjective self-diagnosis):

was diagnosed with this [depression] last august [T1.1*]

the psychiatrist was amazed... he said that I am really depressed [T2.1]

I went to the doctor and he told me I was suffering from depression [T5.1] 
I've been diagnosed with depression [T6.1]

*Thread 1. First post

The doctor references in these accounts works to position the 'speaker' as an authentic patient who is eligible to seek help on this forum; his depression is 'real' as it has been pronounced by an external, expert source. The 'fact' of depression is reinforced with details (e.g. time of diagnosis) and extreme case formulations (e.g. 'really depressed') (see Pomerantz, 1986; Potter, 1996). Depression accounts were also typically reinforced with medication talk, often citing precise technical detail as to drug names, doses, and duration: ...and put on 10mg of citalopram. Was on these for 6 months [T1.1] ...a 6 month course of 10mg citalopram [T3.1]

He gave me Fluoxetine 20mg [T5.1]

...the doctor has prescribed me citalopram 10mg a day. Been on them for about a month now [T6.1]

Such medication talk can imply diagnosis by a doctor, and therefore positions the speaker as a genuine patient, even if this is not explicitly mentioned. Again, detailed descriptions are more convincing (Potter, 1996), something we also see when symptoms of depression are invoked:

...my symptoms which were loss of appetite, confidence, heart palpitations, unable to sleep, tearful, etc [T2.1] ...panic attack last night and had thoughts about suicide [T5.1] dropped some weight [T6.1]

These symptoms match official medical checklists, and we know that listing items can help to build up a persuasive account (see Jefferson, 1991). Beyond psycho-medical discourse, we know that vivid detail within anecdotes recounting specific life events presents 
the account as factual:

...Friday night involved a lot of drink and drugs and I \%\&*\$\# everything up with

her... My CLOSEST friend made a stupid comment and I ended up throwing

him on the sofa and smacking the crap outta him [T19.1]

In this example details of substance abuse, relationship strife and violence are presented, three well established markers of stress or depression for men (Addis, 2008). The extreme case formulations used underline the seriousness of the matter ('a lot'; 'everything'; 'CLOSEST’).

Doing support: response posts

How do other men on the forum respond to these first posts which document experiences of depression? We know that in general responding posts tend to 'mirror' aspects of the first post, and serve as a 'me too’ echo (e.g. Stommel \& Koole, 2010):

was diagnosed with this last month and put on 10mg of citalopram [T1.1]

I was diagnosed a couple months ago - currently on 40mg [T1.2*]

*responding post

In this example, the same discourse around diagnosis and medication is produced in the response, and as with first posts such diagnosis talk establishes the depressed credentials of the responder as someone qualified to understand the issue and respond appropriately. Such medical discourse also protects the responder from being perceived critically (e.g. 'showing off', 'being a know-it-all', 'being a do-gooder') - the responder has no personal agenda and is merely supporting a fellow sufferer. This strategy is known as ‘stake inoculation’ (see Potter, 1996).

Since in this case the community of practice is not restricted to diagnosed participants, 
however, the second post may alternatively mirror medication, symptoms, coping strategies etc. mentioned in the first post:

.... slight ringing/buzzing in my ears [T3.1]

I have occasional ringing in my ears... no idea if it is stress related. [T3.2]

Further, different responders in the same thread may mirror different aspects of the first post, depending on the resources available to them, for example whether they have been diagnosed or not. It thus follows that the more detailed the first post description, the better the chance of a response, since there are more possibilities for mirroring. In cases where responders have no direct personal experience of depression, there is more work to do so that a right to reply is established. For example, they may mirror via the proxy of friends, relatives, etc. Here are three sample responses which reference others:

...my dad has it...[T3.4]

I know people who have various serious mental health problems... [T18.2]

My friend has just been prescribed Betablockers to help out... [T20.2]

Where responders cannot mirror any aspects of the first post, they typically begin instead with a stake-inoculation (Potter, 1996), thereby suggesting that this absence is accountable:

Not suffered myself mate but... glad to hear you are addressing the issue [T6.2]

I don't think I can give the best advice here [T26.3]

I'm not qualified to give advice but... I didn't want to leave this unanswered [T25.2]

Mate I'm crap at advice, but... [T11.2]

Here, the lack of experience of depression is foregrounded in order to diminish its significance and to enable support to then be delivered. A potential issue for men wanting to 
respond to first posts is that providing support or advice positions the responder as an expert, someone sufficiently experienced who knows more than first post contributors - thereby creating a potential power imbalance within a community of peers. In order to counteract or mitigate this impression, responders often deploy informal bonding terms (“mate”, "buddy”, “fella”) (see Bennett \& Gough, 2013).

Undiagnosed symptoms: first posts and responses

Men without a diagnosis who want support from forum members are in a difficult position - how can they construct a credible account without the foundation of medical discourse (doctor, diagnosis, drugs)? It is clear from the forum threads that only doctors are recognised as entitled to diagnose - any self-diagnosis is therefore constructed very carefully, hedged, or downplayed:

I saw a clip on Current TV called 20's meltdown that sort of explains what I'm going through right now...I know I'm not depressed or anything [T15.1]

In this example, the contributor stake-inoculates against appearing to self-diagnose (i.e. against trying to get sympathy), suggesting that he is aware of the norm against it. This hedging formulation is perhaps also designed to attract a validating response, as evidenced in the construction of suicidal identities online (see Horne \& Wiggins, 2009). In contrast, the direct assertion of (self-) diagnosis typically arouses doubts about authenticity:

I am depressed. Please help [T29.1]

Helicopter [T29.2]

PM [personal message] me... if you are actually being serious [T29.3]

It is unclear what 'helicopter' means in this context, but it does not seem supportive; the 'actually' in the other response casts doubt on the veracity of the self-diagnosis. As responders also do not provide diagnoses, this reinforces diagnosis as a responsibility for 
doctors only. Without a diagnosis, reference to symptoms is the primary strategy for working up a depressed account, but because of the likely rejection or criticism from others, contributors deploy additional strategies to validate their account (see Dickerson, 1997). For example, they may invoke significant others as a source of external corroboration:

my wife has noticed a change in my behaviour...[T7.1]

Another complication for those without a diagnosis is the wider community norm around proactive self-management of health - in fact a common feature of men's health discourse more widely (see Courtneay, 2000; Gough, 2009). In other words, these men need to strike a fine balance between appearing depressed and appearing proactive - or between being 'defective' and being 'effective'. Accountability is a live issue here - the men need to avoid any intimation that they might be overly passive or personally responsible for their depressed condition. Accordingly, they may emphasise factors beyond their control:

child access case [T2.1]

recent relationship trauma [T2.1]

death in the family [T3.1]

grandmother passed away [T6.1]

neurological episodes/strokes [T26.1]

extreme migraines [T26.1]

Where some element of personal blame might be possible ('relationship trauma'; 'child access case' [T2.1]), this is deflected by constructing the behaviour of others as unreasonable: the ex ending it... after I had supported her through her problems [T2.1] split up with my ex... she is pregnant with someone elses baby [T25.1] my line manager especially is treating me borderline bullying [T26.1] 
Where attributing responsibility to others is difficult or impossible, contributors locate their accountability in the past and emphasise a more enlightened contemporary situation:

i wasnt helping myself with my binge drinking but i do have some control over this now [T25.1]

So, men without a diagnosis are doubly disadvantaged - they cannot rely on medical discourse to bolster their depression story, and they have to be careful to manage accountability issues to ensure that they are not perceived as inactive or blameworthy.

For those men responding to such undiagnosed accounts, there is great reluctance to offer a confirming diagnosis (as only doctors can do this); instead, the responses often culminate in a suggested visit to the local surgery. As noted by prior studies (Giles \& Newbold, 2011; Stommel \& Meijman, 2011; Vayreda \& Antaki, 2009) this onward referral to formal support positions diagnosis as the preferred 'entry-ticket' for forum support. If selfdiagnosis was tolerated, then anyone could claim to be genuinely depressed, and so all posts and replies would have to be treated as equally serious and credible.

As well as directing 'depressed' men without a diagnosis towards medical consultation, responders also suggest various self-help strategies, in keeping with the online men's health community norm (Gough, 2009):

Go to your doctor... lot's of exercise, no alcohol, massages, talking about it to friends/ family, breathing techniques [T7.2]

See a doctor...learn a new sport or start intensive training at the gym [T15.2]

doctors asap... get more hobbies like say sports meet people keep busy [T22.2]

Go to the doctor... there are other options available to you other than drugs that also work [T23.2] 
Although talking about problems is sometimes advocated (e.g. T7.2 above), many more responding posts propose more action-oriented strategies (sport, training etc.), thereby reinforcing the conventional association of masculinity with the external, physical world rather than the internal, psychological world (Courtenay, 2000; Rochlen et al., 2010). A common strategy for balancing the conflicting effective (men's health norm) and defective (depressed norm) requirements is for first posters to demonstrate that they have indeed adopted a sustained proactive approach to health self-management, but that despite their best efforts it is simply not sufficient to overcome a problem of such magnitude. Help-seeking is thus presented as a last resort, once all self-help efforts have been exhausted:

I am determined to get through this. I have been doing my very best to get out and see people, offload and keep busy, but it's not enough to get me out of this hole [T2.1]

iv bought tesco omega 3 fish oil tabs and their multi vitamins and minerals tab to aid my recover and dont know if i can take them while on my medication [T6.1]

I know what $\mathrm{i}$ want to do i could get my eating right go to the gym and lead a healthy life style for a few months with everything planned but just cant motivate myself to do it [T17.1]

In this context medication is construed as a 'necessary evil', at odds with a preference for selfmanagement:

...I don't want to take drugs... [T8.1]

You are right to try to avoid drugs [T8.2]

....a course of antidepressants just to get myself back on the track... I'm aware they won't solve all my problems, but merely getting me mentally back into a state where I want to 
work out, get up in the morning and generally operate on a basic level would be great, a means to an end [T23.1]

In these accounts medication is not a choice but rather a path down which they have been forced ('put on' [T1.1]; 'told me', 'have to go back' [T5.1]).

\section{Discussion}

Our analysis contributes to literature on men and depression by considering men's accounts in a 'naturalistic' online context (rather than researcher-generated interviews or focus groups), and by highlighting the complex issues around accountability and identity that need to be negotiated when producing a depression story and seeking (and receiving) support from other men. In particular, we show how medical discourse (diagnosis, medication etc.) is implicated in legitimising a depression account and receiving support from others on the forum. We also illustrate the difficult task facing men without a diagnosis and the strategies deployed by these men to reinforce their accounts (e.g. symptom talk, invoking other assessments, deflecting personal responsibility, foregrounding self-help efforts). Finally, we note the reluctance of responders to confirm any self-diagnoses, and to recommend medical consultations, thereby underlining the exclusive role of doctors in categorising people as depressed.

Whilst previous studies (Giles \& Newbold, 2011; Stommel \& Meijman, 2011; Vayreda \& Antaki, 2009) do indeed note the significance of formal diagnosis in overcoming online forum entry-barriers, and the prevalence of 'mirroring' within responses, our analysis casts light on the key issue of accountability with a men's health context, and how it requires very careful attention in both first and response posts. In addition, previous work has not considered that forum support can conversely act to overcome the entry-barriers of formal support, thereby forming a reciprocal relationship (our analysis indicates that responders often propose a visit to the doctor). Since diagnosis acts a ticket for forum entry, and it is 
evident that participants not only seek informal peer support prior to receiving formal help, but that they continue to seek it afterwards. This suggests that such informal support should not only be regarded as simply part of the decision-making process for seeking formal help, as suggested by others (Möller-Leimkühler, 2002). The responses to first posts also suggest that self-management, peer-support, and formal help take place concurrently rather than in a linear sequence. The common medicalised linear narrative, where formal help is regarded as a 'proper' end-point treatment following previous maladaptive attempts at self-management, can therefore be regarded an artefact of the way in which participants are typically recruited from formal health system - and of the interview structure itself (where questions typically progress from early signs to diagnosis, treatment and coping).

Clearly, our data suggest that the entitlement for help may be dependent on the judgment of others concerning the perceived validity of the depression account (e.g. via diagnosis talk and/or attributional work concerning responsibility for the condition and its management). This is in contrast to formal medical help where, at least theoretically, people should be entitled to help irrespective of any attribution of personal responsibility. Consequently, we are suggesting that online support might actually be harder to access than formal support. This is significant since online support group forums are commonly proposed as alternative sources of support for men unwilling to seek formal help, in line with stereotypical 'masculine' attributes (e.g. technical, asocial, anonymous) (e.g. www.men'shealthforum.org.uk). The obvious implication from this analysis is that the process of help-seeking should be less accountable. For example, the ability to make responding posts could be restricted to trained semi-formal approved peer-support experts who were instructed to be non-judgmental and to treat all posts seriously. Whilst posts and replies remained public, and anyone could initially post, the need to competently justify help seeking would be removed, and so alleviate any fear of rejection. Furthermore, this initiative 
would also remove the preference for 'diagnosis', and thereby the barrier presented by any stigma associated with medicalised mental-health issues.

Unlike existing private one-to-one online consultations with medical professionals (e.g. ManMOT, 2011), this would retain the benefit of providing public information for 'lurkers' with similar problems, as well as any accessibility benefits of peer rather than formal support. This system would be similar to a newspaper 'agony aunt' or 'consumer troubleshooter', or some online technical support 'knowledge-bases' provided by computer manufacturers. Such a focus on increasing accessibility by reducing accountability may also be similarly applicable to 'real-world' support, suggesting a future area of research. For example, any perceived accountability of doctor consultations might be removed by the availability of a physical 'golden-ticket' invitation, the simple possession of which is sufficient to do the accounting.

Our analysis is obviously limited to one UK-based website, and further research is required examining men's accounts on other website forums dedicated to male mental health issues (and indeed on those websites not ostensibly geared towards mental health but which nonetheless produce relevant threads) in order to test out our analysis and recommendations. In addition, it must be acknowledged that there will be depressed men who do not post on discussion forums like the one featured here, so we cannot claim that our analysis extends to men who merely observe forum posts or those who do not access or engage with online forums at all. Although we focused on issues of authenticity and accountability in common with other discursively-oriented studies of distress, there are other relevant topics which might be considered further when studying men’s (online) depression talk, including the place and meaning of humour in forum discussions around depression, the ways in which significant others (e.g. partners, friends, family) are invoked as sources of support (and further stress!), and the construction of health professionals in the diagnosis and treatment of 
depression. It would also be fruitful to move beyond first and second posts to study how particular threads unfold over time with multiple participants - this type of analysis would further illuminate the discourse dynamics at play while providing a greater appreciation of a community under construction. We also recognise that the emphasis on language use and function in this analysis would not satisfy other qualitative researchers who use different methodologies, such as phenomenological approaches (e.g. Smith, 1996), where the focus might be on individual lived experience instead.

In sum, our analysis highlights the complex discursive work undertaken by men experiencing depression and seeking help. It builds on previous quantitative and interviewbased research by studying men in a 'naturalistic' (online) context and emphasising the dynamic and diverse ways in which depression may be formulated by men and their peers within a broadly supportive community environment. In contrast to much established research where 'masculinity' is explicitly used as a lens to understand men's interview-based accounts of depression and coping (e.g. Oliffe et al., 2010; Rochlen et al., 2010; Valkonen \& Hänninen, 2013) , we did not assume that 'masculinity' would be a relevant or central concern for the men in our dataset. In the event traditional notions of 'masculinity' were referenced indirectly at times; for example, a lot of advice on the forum centred around selfmanagement and practical activities (e.g. physical exercise) rather than talking therapies, as noted in other studies (e.g. Emslie et al., 2006). It is also interesting to note that men do access and engage with peer support online as well as (or in some cases perhaps in preference to) seeking more formal help - help-seeking may be more acceptable to men online rather than face-to-face (see also Bennett \& Gough, 2013). Nonetheless, what is striking about our analysis is that concerns about authenticity and accountability - concerns highlighted in other online support group studies - were more prevalent and arguably more relevant than any masculinity issues. This point suggests that researchers investigating male mental health 
might pay closer attention to what men themselves make relevant rather than analysing men's accounts with particular masculinity constructs already in mind and presumed to be influential in how men express and cope with depression.

\section{References}

Addis, M. E. (2008). Gender and Depression in Men. Clinical Psychology: Science and Practice, 15, 153-168.

Addis, M. E., \& Cohane, G. H. (2005). Social scientific paradigms of masculinity and their implications for research and practice in men’s mental health. Journal of Clinical Psychology, 61, 633-647.

Bennet, E. \& Gough, B. (2013). In Pursuit of Leanness: Constructing bodies and masculinities online within a men’s weight management forum. Health, 17, 284-99

British Psychological Society. (2013). Guidelines for Internet-mediated Research. Retrieved December 13, 2013, from: http://www.bps.org.uk/system/files/ Public\%20files/inf206-guidelines-for-internet-mediated-research.pdf.

Braun, V. \& Clarke, V. (2006). Using thematic analysis in psychology. Qualitative Research in Psychology, 3, 77-102.

Connell, R. W. (2005). Masculinities (2nd ed.). Cambridge: Polity Press.

Connell, R. W. \& Messerschmidt, J. W. (2005). Hegemonic Masculinity: Rethinking the Concept. Gender \& Society, 19, 829-859.

Courtenay, W. (2000). Constructions of masculinity and their influence on men's well-being: a theory of gender and health. Social Science and Medicine, 50, 1385-1401.

Cutcliffe, J. R., McKenna, H., Keeney, S., Stevenson, C., \& Jordan, J. (2013). 'Straight from the horse's mouth': rethinking and reconfiguring services in Northern Ireland in response to suicidal young men. Journal of Psychiatric and Mental Health Nursing, 20, 466-472. 
Dickerson, P. (1997). It’s not just me who’s saying this...': The deployment of cited others in televised political discourse. British Journal of Social Psychology, 36, 33-48.

Emslie, C., Ridge D., Ziebland S., \& Hunt K. (2007). Exploring men's and women's experiences of depression and engagement with health professionals: more similarities than differences? A qualitative interview study. BMC Family Practice, 8 , $1-10$.

Emslie, C., Ridge, D., Ziebland, S., \& Hunt, K. (2006). Men's accounts of depression: Reconstructing or resisting hegemonic masculinity? Social Science \& Medicine, 62, 2246-2257

Giles, D.C. \& Newbold, J. (2011). Self- and other-diagnosis in user-led online mental health communities. Qualitative Health Research, 21, 419-28.

Gough, B. (2009). Promoting `Masculinity` Over Health: A Critical Analysis of Men`s Health Promotion With Particular Reference to an Obesity Reduction `Manual’, in B. Gough \& S. Robertson (Eds.) Men, Masculinities and Health: Critical perspectives. (pp.125-143). Basingstoke: Palgrave.

Gray, B. (2004). Informal learning in an online community of practice. Journal of Distance Education. 19(1): 20-25.

Horne, J. \& Wiggins, S. (2009). Doing being 'on the edge': managing the dilemma of being authentically suicidal in an online forum. Sociology of Health \& Illness, 31, 170-184.

Horton-Salway, Mary (2001). The Construction of ME: the discursive action model. In: Wetherell, Margaret; Taylor, Stephanie and Yates, Simeon J. eds. Discourse as data: a guide to analysis. UK: Sage Publications Ltd, 147 -188

Jefferson, G. (1991). List construction as a task and a resource. In G. Psathas (Ed.) Interactional Competence. (pp.63-92). New York: Irvington Publications. 
Johnson, J. L., Oliffe, J. L., Kelly, M. T., Galdas, P., \& Ogrodniczuk, J. S. (2012). Men’s discourses of help-seeking in the context of depression. Sociology of Health \& Illness, 34, 345-361.

Lamerichs, J. \& Molder, H.F.M. te (2003). Computer-mediated communication: from a cognitive to a discursive model. New Media \& Society, 5, 451-473.

Mahalik, J. R., Burns, S. M. \& Syzdek, M. (2007). Masculinity and perceived normative health behaviors as predictors of men's health behaviors. Social Science \& Medicine, 64, 2201-2209.

Messerschmidt, J. W. (1993). Masculinities and Crime: Critique and reconceptualization of theory. Lanham, MD: Rowman \& Littlefield.

Möller-Leimkühler, A.M. (2002). Barriers to help-seeking by men: a review of sociocultural and clinical literature with particular reference to depression. Journal of Affective Disorders, 71, 1-9.

Möller-Leimkühler, A. M. (2003). The gender gap in suicide and premature death or: why are men so vulnerable? European Archives of Psychiatry and Clinical Neuroscience, 253, $1-8$.

Morrison, L., Trigeorgis, C. and John, M. (2014) Are mental health services inherently feminised? The Psychologist, 27[6]: 414-416

NICE (2009a) Depression. The treatment and management of depression in adults (NICE guideline). Clinical guideline 90. National Institute for Health and Care Excellence. www.nice.org.uk 
Oliffe, J. L., Ogrodniczuk, J. S., Bottorff, J. L., Johnson, J. L., \& Hoyak, K. (2012). “You feel like you can’t live anymore": Suicide from the perspectives of Canadian men who experience depression. Social Science \& Medicine, 74, 506-514.

Oliffe, J.L., Han, S.C., Ogrodniczuk, J.S., Phillips, J.C. \& Roy, P. (2011). Suicide from the Perspectives of Older Men who Experience Depression. American Journal of Men's Health, 5, 444-454.

Oliffe, J. L., Robertson, S., Kelly, M. T., Roy, P., \& Ogrodniczuk, J. S. (2010). Connecting masculinity and depression among international male university students. Qualitative Health Research, 20, 987-998.

Pomerantz, A. (1986). Extreme case formulations: a way of legitimizing claims. Human Studies, 9, 219-229.

Potter, J. (Ed.)(2007). Discourse and Psychology: Volumes I, II and III. London: Sage.

Potter, J. (1996). Representing Reality: Discourse, rhetoric and social construction. London: Sage.

Potter, J. \& Hepburn, A. (2005). Qualitative interviews in psychology: Problems and possibilities. Qualitative Research in Psychology, 2, 281-309 .

Ramirez, J. L., \& Badger, T. A. (2014). Men Navigating Inward and Outward Through Depression. Archives of Psychiatric Nursing, 28, 21-28.

Richards, D. A. \& Borglin, G. (2011). Implementation of psychological therapies for anxiety and depression in routine practice: Two year prospective cohort study. Journal of Affective Disorders, 133, 51-60.

Ridge, D., Emslie, C., \& White, A. (2011). Understanding how men experience, express and cope with mental distress: where next? Sociology of Health \& Illness, 33, 145-159.

Robertson, S., Hanna, E., Raine, G., Robinson, M., Seims, A., Gough, B. \& White, A. (2014) What works for boys in men ain mental health promotion?, report for Movember. 
Robertson, S. \& Williams, R. (2009) Men: Showing willing. Challenging common assumptions and considering men's own accounts will help health practitioners to understand men’s use of health services, Community Practitioner, 82[4]: 34-35.

Rodham, K., \& Gavin, J. (2006). The ethics of using the internet to collect qualitative research data, Research Ethics Review, 2, 92-97.

Rochlen, A. B., Paterniti, D. A., Epstein, R. M., Duberstein, P., Willeford, L., \& Kravitz, R. L. (2010). Barriers in diagnosing and treating men with depression: a focus group report. American Journal of Men's Health, 4, 167-175.

Rochlen, A. B., Whilde, M. R., \& Hoyer, W. D. (2005). The Real Men. Real Depression Campaign: Overview, Theoretical Implications, and Research Considerations. Psychology of Men \& Masculinity, 6, 186-194.

Roy, P., Tremblay, G., \& Robertson, S. (2014). Help-seeking among Male Farmers: Connecting Masculinities and Mental Health. Sociologia Ruralis, (e-publication ahead of print). doi: 10.1111/soru.12045

Seymour-Smith, S. (2013). A reconsideration of the gendered mechanisms of support in online interactions about testicular implants: a discursive approach. Health Psychology, 32, 91-99

Sierra Hernandez, C. A., Han, C., Oliffe, J. L., \& Ogrodniczuk, J. S. (2014). Understanding Help-Seeking Among Depressed Men. Psychology of Men \& Masculinity, 15, 346354.

Smith JA (2004) Reflecting on the development of Interpretative Phenomenological Analysis and its contribution to qualitative research in psychology. Qualitative Research in Psychology 1: 39-54.

Speer SA. (2008). Natural and contrived data. In P. Alasuutari, J. Brannen and L. Bickman 
(eds.) The Sage Handbook of Social Research Methods. (pp. 290-312). London: Sage

Stommel, W. \& Meijman, F.J. (2011). The use of conversation analysis to study social accessibility of an online support group on eating disorders. Global Health Promotion 18, 1-9.

Stommel, W. \& Koole, T. (2010). The Online Support Group as a community. A microanalysis of the interaction with a new member. Discourse Studies, 12, 357-378.

Tamres, L. K., Janicki, D., \& Helgeson, V. S. (2002). Sex differences in coping behaviour: A meta-analytic review and an examination of relative coping. Personality and Social Psychology Review, 6, 2-30.

Valkonen, J. \& Hänninen, V. (2013). Narratives of masculinity and depression. Men and Masculinities, 16, 160-180.

Vayreda, A. \& Antaki, C. (2009). Social Support and Unsolicited Advice in a Bipolar Disorder Online Forum. Qualitative Health Research, 19, 931-942.

Walther, J. B. \& Boyd, S. (2002). Attraction to computer-mediated social support. In C. Lin \& D. Atkin (Eds.), Communication Technology and Society. Audience adoption and uses (pp.153-188). Cresskill, NJ: Hampton Press.

Wenger, E. (1998), Communities of practice: learning, meaning, and identity. Cambridge University Press: Cambridge. 